\title{
Papers
}

\section{The implications of incomplete and spurious personal information disclosures for direct marketing practice}

Received (in revised form): 24th October, 2005

\section{Gary S. Robertshaw}

is a fellow of the Institute of Direct Marketing. He gained his PhD in Database Marketing from the University of Huddersfield and has published previously in the Journal of Direct, Data and Digital Marketing Practice, Journal of Financial Services Marketing, Journal of Empirical Generalisations in Marketing Science, Journal of Database Marketing and Journal of Segmentation in Marketing. He is a marketing manager at a leading UK insurance company.

\section{Norman E. Marr}

is Professor of Marketing at the Huddersfield University Business School. He completed his PhD in Logistics and Marketing at Cranfield School of Management and has published work in a wide variety of both academic and vocational international journals. He previously held a number of academic positions in New Zealand.

Gary S. Robertshaw 15 Heron Close, Mountain, Queensbury, Bradford, West Yorkshire, BD13 1NR

Tel: +44 (0) 1274884387 e-mail: g.robertshaw@ btopenworld.com

Abstract The self-disclosure of non-transactional, individual-level consumer information for direct marketing purposes - eg interests, beliefs, competitor spending habits and future purchase intentions - is essentially voluntary in nature. This raises the possibility that such information may be to some degree incomplete and unreliable. A review of the literature, however, reveals that this has received little attention and, consequently, the implications for direct marketing practice have been overlooked.

Using 157 personal interviews, this study quantifies typical levels of personal information omission and falsification in voluntary disclosures. The types of personal information that consumers tend to omit and falsify are identified, and an understanding of the underlying reasons is provided with a consideration of the implications for direct marketing practice.

Whilst the findings indicate typically low levels of personal information omission and falsification, these are shown to have a potentially significant impact on the profitability of companies employing direct marketing methods.

\section{BACKGROUND}

Market fragmentation and heightened consumer eclecticism are accelerating the abandonment of mass marketing methods in favour of personalised marketing programmes that better meet the needs of the individual. ${ }^{1,2}$ This shift towards personalised forms of marketing has been accentuated by the advent of digital communication channels including the internet, interactive television and mobile telephones, allowing the direct marketing industry to increasingly communicate and interact with individual consumers on a real-time basis. ${ }^{3}$

Single decisions to target one market 
segment are now being superseded by millions of independent automated decisions to communicate with individual consumers at an appropriate time. Mass marketing communications in single batches personalised to meet the specific requirements of the individual consumer are now both possible and profitable. ${ }^{4}$

Given its unique ability to recognise, acknowledge, appreciate and serve the interests and needs of the selected consumers whose individual identities and profiles can be acquired, fragmenting markets have become a source of incremental competitive advantage for the direct marketing industry. ${ }^{5}$

The evolution and development of personalised marketing programmes is, however, critically dependent on the availability of detailed, individual-level consumer information. All modern personalised targeting models including artificial neural networks and all customer profiling and data appending practices, typically incorporate such information. Whilst individual-level transactional data can be obtained from customer records, the acquisition of insightful, non-transactional information relating to interests, beliefs, values, opinions, competitor spending habits, future purchase intentions, religion, political affiliation, television viewing habits and a multitude of other lifestyle characteristics essentially relies on voluntary consumer disclosure.

The collection of non-transactional, individual-level information for direct marketing purposes is based on the premise that consumers can be persuaded to voluntarily disclose personal details as a result of some type of marketing exchange process. This is usually in anticipation of some perceived benefit and includes surveys and questionnaires, direct mail and telephone orders, loyalty cards, product warranty cards, replies to direct response ads, sweepstake promotions and rebate and redemption offers. ${ }^{6,7}$

The experience of companies collecting individual-level consumer information within the UK indicates that a majority of consumers are prepared to disclose such information in various different forms ${ }^{8,9}$ subject to adequate data protection safeguards and evidence of benefits arising from disclosure. ${ }^{10}$

\section{EFFECT OF INCOMPLETE AND FALSIFIED PERSONAL INFORMATION ON COMPANY PROFITABILITY}

Though the amount of individual-level consumer information being gathered continues to expand, there are few studies that have evaluated how complete and reliable such information is. Consequently, the implications for direct marketing practice have received little attention. This is an important gap in knowledge because incomplete and falsified information reduces the efficiency of the direct marketing effort. Commercial decisions affecting company profitability are often made with a reliance on consumer veracity in disclosing personal information.

Companies offering credit facilities including retailers, credit card and mail order companies - often set initial credit limits on new applicants based on self-reported income and other variables such as date of birth, marital status, employment status, time at current address, residential status, occupation, time in occupation and other credit cards held. A company using individual-level consumer information that is to some degree spurious may encounter increased bad debt and payment default propensities as a consequence of setting inaccurate initial credit limits from incorrectly targeted communications. ${ }^{11}$

Specialist motor insurance companies 
also depend on the reliability of voluntarily disclosed personal information when targeting new customers according to specific underwriting criteria. These underwriting criteria are used to establish insurance premium levels and include an individual's postcode, vehicle make and model, occupation and date of birth. The use of falsified information leads to misclassified market segments being targeted, thereby reducing the effectiveness of the direct marketing communication.

The adverse effects of falsified and omitted personal information disclosures on company profitability are not limited to the targeting of new customers. Transactional data alone is insufficient for understanding purchase behaviours because it provides little insight into the needs that motivate and shape the purchase process and lacks details such as competitor spend and future purchase intentions. ${ }^{12}$ Radford's study, ${ }^{13}$ for example, described how the Co-operative Bank successfully abandoned its sole use of transactional data in favour of supplementing its customer records with lifestyle characteristics to gain greater insight that contributed to increased profitability. Accordingly, many companies are now appending externally acquired individual-level information to their transactional databases in an attempt to learn more about their customers. Again, omissions and inaccuracies in the acquired information potentially lead to misclassification of customers in the database and personalisation error. As a consequence, companies cannot be as precise in their customisation, which ultimately diminishes the efficiency of the direct marketing effort.

\section{METHODOLOGY}

The objectives of this study were to quantify typical levels of personal information omission and falsification; identify the types of personal information that tend to be omitted and falsified; gain an understanding of the underlying reasons for their occurrence; and consider the implications for direct marketing practice.

Personal interviews were chosen as the most appropriate data collection method because they allowed more complete and informed responses to be elicited. In addition, it was possible to monitor facial expressions and body language that communicated emotions, motivations and attitudes not apparent from non-direct methods of data collection, adding greater depth in qualitative understanding. The personal interviews were conducted in a busy West Yorkshire city centre.

Throughout, reassurance of confidentiality of the results was emphasised and the interviews proceeded in a conversational manner. The responses were written down during the interviews and further notes relating to facial expressions, emotions and feelings added on completion of each interview.

Consistency in the manner in which the questions were posed and in surroundings was maintained to reduce the context dependency of responses; for example, the immediate environment, interviewee mood, comfort and recent experience.

The target population consisted of all of the individuals who disclosed personal information for direct marketing purposes. In recognition that personal interviews typically have a higher degree of geographical bias, and the potential for introducing non-coverage issues such as response-bias, ${ }^{14}$ the target population was defined using a proportionately stratified, nationally representative sampling frame.

The target population was stratified according to three age bands and gender, - a total of six strata. Approximately one third of the target population was 
Table 1: National proportion of individuals per stratum

\begin{tabular}{lcc}
\hline Age group & Male & Female \\
\hline $18-34$ & $14 \%$ & $16 \%$ \\
$35-54$ & $18 \%$ & $18 \%$ \\
55 and over & $16 \%$ & $18 \%$ \\
\hline
\end{tabular}

Table 2: Actual proportion of interviewees per stratum

\begin{tabular}{lllll}
\hline Age group & Male & $\begin{array}{l}\text { Percentage } \\
\text { of total }\end{array}$ & Female & $\begin{array}{l}\text { Percentage } \\
\text { of total }\end{array}$ \\
\hline $18-34$ & 20 & $13 \%$ & 26 & $17 \%$ \\
$35-54$ & 27 & $17 \%$ & 30 & $19 \%$ \\
55 and over & 27 & $17 \%$ & 27 & $17 \%$ \\
\hline
\end{tabular}

assigned to each age band to ensure that the six strata were similar in size. This allowed interviewees to be assigned to each stratum without the requirement for weighting. Quota sampling as a method of stratification was dismissed because the selection process within strata relies on the discretion of the interviewer. Whilst it is an easier method of conducting interviews, it is more unreliable and prone to bias because it is essentially non-random in nature.

Individuals were approached as potential interviewees on a random basis, regardless of gender, age, outward appearance and whether alone or in a group. In those cases where an interview commenced and the interviewee stated that he or she did not voluntarily disclose personal information for direct marketing purposes then no further questioning regarding omission and falsification was undertaken. Only contributors of personal information were included in the study.

Where a group of two or more individuals was approached, the first individual electing to participate was chosen and this individual was then asked to answer questions in isolation and far enough away that responses could not be heard, preventing third party influence. This was an important procedure, because respondents may have otherwise have been tempted to answer in a manner that gave them credibility in the presence of onlookers, rather than providing truthful responses.

A total of 157 personal interviews were conducted to ensure that an adequate, proportionately stratified sample frame was obtained. Table 1 shows the national proportion of individuals within each gender and age-defined stratum and Table 2 shows the actual proportion of interviewees obtained per stratum. The proportions of interviewees per stratum broadly corresponded to that of the national population.

It was noted that nationally representative results typically involve sample sizes in excess of 1,000 respondents. ${ }^{15}$ The results obtained from this study therefore involved a sample size that could not be generalised across the national population. Accordingly, the results of this study must be regarded as indicative in nature rather than confirmative.

The personal interviews began by informing respondents of common direct marketing data gathering practices including consumer surveys and questionnaires, warranty card surveys, telephone and internet registrations and loyalty card applications. Interviewees were then asked: 'Do you disclose personal information for direct marketing 
Table 3: Incidence of omissions in disclosed personal information

\begin{tabular}{lccc}
\hline Response & Observed number & Percentage & Expected number \\
\hline All of them & 24 & $15 \%$ & 31.4 \\
More than half & 49 & $31 \%$ & 31.4 \\
Roughly half & 50 & $32 \%$ & 31.4 \\
Less than half & 20 & $13 \%$ & 31.4 \\
Hardly any & 14 & $9 \%$ & 31.4 \\
TOTAL & $\mathbf{1 5 7}$ & $\mathbf{1 0 0 \%}$ & $\mathbf{1 5 7 . 0}$ \\
\hline
\end{tabular}

purposes?' Those interviewees who answered yes were asked: 'When disclosing personal information, how many of the questions do you typically complete?' and asked to rate their answers on the following scale i) all of them, ii) more than half, iii) roughly half, iv) less than half, v) hardly any. Where an interviewee stated that they omitted information, the question: "What type of questions are you least likely to answer and why?' was posed.

Next, interviewees were asked: 'How often do you knowingly provide false information?' and, again, rate their answer i) never, ii) not very often, iii) sometimes, iv) often, v) very often. Those interviewees who admitted falsifying personal information were asked: 'What type of questions are you likely to falsify and why?' Interviewees were reassured of confidentiality at this stage due to the sensitive nature of the questioning and were encouraged to be as truthful as possible in their responses.

\section{RESULTS AND DISCUSSION}

\section{Prevalence of omissions}

Table 3 shows that only a minority (15 per cent) of interviewees typically disclosed all information requested. Whilst 78 per cent completed half or more of the questions posed, a small minority ( 9 per cent) reported that they completed 'hardly any' questions. Essentially, these findings indicated that the majority of personal information disclosed for direct marketing purposes is, to varying degrees, incomplete.

The hypothesis that there is a skew in consumers' propensity to omit specific details when disclosing personal information for direct marketing purposes was assessed using the goodness-of-fit Chi-square test.

There is no skew in consumers' propensity to omit specific details when disclosing personal information for direct marketing purposes (null hypothesis).

There is a skew in consumers' propensity to omit specific details when disclosing personal information for direct marketing purposes

(alternative hypothesis.

Table 3 provides a $\chi^{2}$ value of 36.3 . Two levels of significance $(\alpha)$ were assessed: 5 per cent and 1 per cent, using 4 degrees of freedom calculated as $\mathrm{k}-1$, where $\mathrm{k}$ is the number of categories. The following critical values were obtained:

$$
\begin{aligned}
& \chi_{0.05,4}^{2}=9.5 \\
& \chi_{0.01,4}^{2}=13.3
\end{aligned}
$$

The null hypothesis was rejected at both levels of significance, supporting the alternative hypothesis that there is a skew in consumers' propensity to omit specific details when disclosing personal information for direct marketing purposes, towards lower levels of such information typically being omitted. 


\section{Typology and reasons underlying omissions}

Only those interviewees who reported that they omitted information were eligible to respond to the question: 'What type of questions are you least likely to answer and why?' This constituted 133 out of the 157 interviewees.

A universal theme to emerge was the unwillingness of interviewees to disclose what they perceived to be sensitive information, particularly information relating to income and health and typified by comments such as: 'private information I'd only give to a doctor or bank' and 'what I consider to be private such as salary or health'. Responses were expressed intensely and affirmatively, emphasising the importance attached to such information.

Interviewees regarded sensitive information as confidential in nature and distinct from less intrusive information such as hobbies and interests: 'salary and health. These are private and not for them to know'. Effectively, these interviewees represented a sub-segment of abstainers; that is, rather than abstaining completely from disclosing personal information for direct marketing purposes they did so selectively. Omission of sensitive information was essentially a selective form of abstention.

These findings were consistent with secondary data obtained from a 2004 UK nationally distributed consumer survey. The source of the survey is not disclosed for reasons of commercial confidentiality. Though only nine variables were made available, the results shown in Table 4 reveal that the propensity of consumers to omit particular types of personal information is related to the type of information requested. More precisely, Table 4 confirms the amenability of
Table 4: Omissions in personal information

\begin{tabular}{ll}
\hline Data variable & Percentage omission \\
\hline Gender & 0 \\
Marital status & 0 \\
Age & 0 \\
Lifestyle interests & 2.6 \\
House type & 3.4 \\
Occupation & 6.7 \\
Number of children & 9.1 \\
Household income & 11.5 \\
Credit card usage & 16.0 \\
\hline
\end{tabular}

consumers towards the disclosure of less sensitive information, such as gender, marital status, age and lifestyle interests. By contrast, financial information such as income and credit card usage were more likely to be omitted.

Having reported the types of personal information they were most likely to omit, interviewees were then asked to elaborate on their reasons for omission. The most prevalent reason underlying omission was data protection concerns; specifically, that sensitive information might be disseminated to third parties leading to intrusion of privacy: 'I'm worried that personal information such as health and finances will be passed on' and 'Very private stuff I don't want passing on'.

Interviewees also omitted information relating to what they perceived to be overly long or complicated questions and where they lacked requisite knowledge to offer an informed response. Effectively information omission offered a route to hastening and simplifying the response process: 'long, drawn out questions that take ages to complete', 'long-winded, difficult and irrelevant questions I miss out' and 'difficult ones I don't understand.'

\section{Prevalence of falsification}

Table 5 shows that only a minority (46 per cent) of interviewees 'never' knowingly disclosed false personal 
Table 5: Incidence of personal information falsification

\begin{tabular}{lccc}
\hline Response & Observed number & Percentage & Expected number \\
\hline Very often & 24 & $15 \%$ & 31.4 \\
Often & 49 & $31 \%$ & 31.4 \\
Sometimes & 50 & $32 \%$ & 31.4 \\
Not very often & 20 & $13 \%$ & 31.4 \\
Never & 14 & $9 \%$ & 31.4 \\
TOTAL & $\mathbf{1 5 7}$ & $\mathbf{1 0 0 \%}$ & $\mathbf{1 5 7 . 0}$ \\
\hline
\end{tabular}

information. However, a total of 76 per cent of interviewees either 'never' or 'not very often' falsified personal information, indicating that the general incidence of corrupted information was relatively low.

The hypothesis that there is a skew in consumers' propensity to falsify specific details when disclosing personal information for direct marketing purposes was assessed using the goodness-of-fit Chi-square test.

There is no skew in consumers' propensity to falsify specific details when disclosing personal information for direct marketing purposes (null hypothesis).

There is a skew in consumers' propensity to falsify specific details when disclosing personal information for direct marketing purposes (alternative hypothesis).

Table 5 provides a $\chi^{2}$ value of 104.3 . Two levels of significance $(\alpha)$ were assessed: 5 per cent and 1 per cent, using 4 degrees of freedom calculated as $\mathrm{k}-1$ where $\mathrm{k}$ is the number of categories. The following critical values were obtained:

$$
\begin{aligned}
& \chi_{0.05,4}^{2}=9.5 \\
& \chi_{0,01,4}^{2}=13.3
\end{aligned}
$$

The null hypothesis was rejected, at both levels of significance supporting the alternative hypothesis that there is a skew in consumers' propensity to falsify specific details when disclosing personal information for direct marketing purposes, towards lower levels of such information being falsified. Incidences of personal information falsification were lower than that for omission. Such information is more likely to be omitted than falsified in response to a perceived threat.

\section{Typology and reasons underlying falsification}

The interviewee sample size was reduced to 84 after excluding those who indicated that they never knowingly provided false information. The most frequently falsified information was that which interviewees perceived to be sensitive, particularly income and health-related questions: 'private questions such as my health or how much money I get' and 'life insurance and questions about your health'. These were essentially the same types of information that interviewees were most likely to omit, revealing commonality in omission and falsification typology. By contrast with the omission of personal information, however, interviewees also reported other types of sensitive information that they were prepared to falsify. These included falsification of questions relating to the environment, diet, alcohol consumption, smoking and charitable donations: 'charities, health, 
diet and other stuff' and 'eating, smoking and drinking'.

Interviewees were then asked to describe their reasons for falsifying personal information. The major reason cited was data protection concerns; specifically concerns that information would be passed to third parties leading to the receipt of unwanted marketing communications, commonly referred to as 'junk mail'. For example, by falsely indicating no interest in a given subject it was believed that marketing communications would be avoided. Again, this was the main reason cited for omission of information. Typical comments included: 'I change information I provide for things such as life insurance, saying I'm not interested because they ring you all the time trying to sell stuff and 'I put "no" against some questions so they won't start sending me junk mail if they think I might be interested, things like a new car or home improvements'.

A further reason for falsification was the desire to appear socially responsible. This situation was particularly pronounced with respect to questions relating to environmental, health and charitable concerns. Interviewees were reluctant to express a lack of ecological concern, to acknowledge poor eating habits or disinterest in charitable affairs: 'I might sometimes exaggerate stuff to look better, like diet and exercise' and 'to appear responsible on things like diet and smoking'. Social conditioning led interviewees to provide what they perceived to be 'correct' answers in the belief that they were acting responsibly.

Finally, interviewees falsified answers to overly long questions on direct marketing data gathering devices and because of difficulty in interpreting the questions and subsequent failure to respond correctly. Falsification thus provided a route to reducing the time and effort involved in the disclosure process: 'to speed up filling in the form, such as saying I'm not interested in a certain thing and jumping to the next section' and 'I might guess the answer wrongly if I don't understand the question'.

\section{Relationship between omission and falsification of personal information}

Given the apparent similarity in reasons underlying omission and falsification of personal information, Pearson's

Correlation Coefficient was used to ascertain if a relationship existed between interviewee propensities to omit and to falsify personal information. Pearson's Correlation Coefficient has a range of +1 (indicating a perfectly positive relationship) and -1 (a perfectly negative relationship). A result of +0.49 was obtained. This positive correlation was tested for statistical significance at the 5 per cent level (1.96) and the 1 per cent level (2.58) using the formula:

$$
\frac{r V(n-2}{V\left(1-r^{2}\right)}
$$

where $r$ is Pearson's Correlation Coefficient and $n$ is the sample size.

A result of +7.00 was obtained, confirming a strong correlation between propensities to omit and to falsify personal information; where there was a high incidence of omitted information there was a correspondingly greater level of falsification.

\section{HYPOTHETICAL ILLUSTRATION OF THE EFFECT ON COMPANY PROFITABILITY}

The quantitative findings from the study were applied to an actual targeting model used by a UK motor insurance company. The objective was to 
determine what effect omission and falsification of voluntarily disclosed personal information had on the company's profitability. For reasons of commercial confidentiality the identity of the company is not disclosed.

The company concerned used external mailing lists compiled from voluntarily disclosed personal information to target new customers whose characteristics met specific underwriting criteria. These criteria were used to establish premium levels based on claims risk and included the driver's occupation, postcode, vehicle make and model, date of birth and insurance renewal date.

Conversion rates, as defined by the number of policies sold against insurance quotations, were 28 per cent within the company's targeted competitive segment. Outside of this segment, conversion rates stood at just 7 per cent. The company concerned mailed 3.2 million prospective customers by post over a 12-month period, aligned with the recipient's stated motor insurance renewal date. Response rates to the mailing were typically 2 per cent.

Hypothetically, if all 3.2 million prospective customers fell within the company's most competitive market segment, based on the assumption that the individual-level consumer information used to compile the mailing lists was wholly accurate and complete, then the company would have expected to acquire the following number of motor insurance policies:

3.2 million $\times 2 \%$ response rate $\times$ $28 \%$ conversion rate $=17,920$ policies

The mean policy premium stood at $£ 325$, equating to a gross written premium of $\mathcal{E}, 5,824,000$.

The findings of this study indicate that 9 per cent of consumers disclose hardly any personal information requested in direct marketing data capture devices. Even assuming the best case scenario, wherein the remaining 91 per cent of consumers provided full details of their date of birth, occupation, postcode, vehicle make and model and insurance renewal date, this indicates that the total mailing universe would have been approximately 3.5 million records had all contributed information been complete. That equates to a lost opportunity of 1,772 policies or $\mathcal{L}^{576,000}$ gross written premium applying the preceding response and conversion rates as a consequence of incomplete information in voluntary disclosures.

There existed no mechanism for screening out falsified personal information in the data processing stages and the insurance company essentially relied on the veracity of such information in targeting new customers. This study suggests that 5 per cent of consumers very often falsify voluntarily disclosed personal information for direct marketing purposes. It can be assumed that this falsification applied to some element of the driver's occupation, postcode, vehicle make and model, date of birth and insurance renewal date thereby resulting in an incorrect assessment of the risk involved in insuring the particular driver. That being the case, 5 per cent of the 3,200,000 mailed records would not fall within the company's target market, equating to 160,000 records. As these 160,000 records would fall outside of the company's most competitive segment, these would convert from quotation to policy at a rate of just 7 per cent. Under these conditions the following number of policies would be acquired:

$$
\begin{aligned}
& {[(3,200,000 \times 95 \%) \times 2 \% \times 28]+} \\
& [(3,200,000 \times 5 \%) \times 2 \% \times 7)]=17,248
\end{aligned}
$$

At a mean policy premium of $\mathcal{E} 325$, the 
gross written premium would then

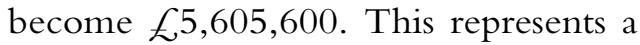
reduction of 672 policies and a loss of $£ 218,400$ gross written premium compared to the situation whereby the personal information used was wholly accurate.

This hypothetical illustration indicates that typically low levels of personal information omission and falsification can have an important detrimental affect on the profitability of companies employing direct marketing methods.

\section{CONCLUSION}

The following limitations in the research should be noted.

First, since the personal interviews were conducted at a single point in time the findings do not reflect future isolated events or changes in social forces that may affect consumer perceptions of direct marketing activities. In particular, levels of public awareness of the collection and use of personal information are likely to increase over time as more businesses embrace direct marketing methods; this will, in turn, increase the prevalence of data protection concerns. This is an important point, because this study has shown that data protection concerns can influence the propensity of consumers to omit and falsify such information. The completeness and reliability of individual-level consumer information may thus be related to changes in the external environment. As a consequence, the results have a limited period of applicability and should be re-tested before being applied to areas of further study.

Secondly, the quantitative findings cannot be generalised across the national population due to the sample sizes used. Accordingly, the study's findings are indicative in nature, rather than laying claim to being conclusive or confirmative.

Consumers have a hierarchy of information that they are prepared to disclose, ranging from relatively harmless details such as name and address, to details of income and personal finance. There is a reluctance to disclose what is perceived as sensitive information whilst greater amenability to the disclosure of more innocuous details. Those companies seeking to acquire more sensitive personal information, particularly that relating to finance and health, are likely to encounter higher rates of omission and falsification in voluntary disclosures. This leads directly to the postulation that the financial services and health-related market sectors will be worst affected by these phenomena. Since omission and falsification of voluntarily disclosed personal information have been shown to erode the profitability of companies relying on such information, the extent of this erosion is likely to be sector specific.

Previous studies have tended to focus on the effects of data protection concerns on willingness to disclose personal information. This represents too narrow an interpretation of the effects of data protection concerns, since such concerns are manifested not solely in terms of a dichotomous choice between voluntary disclosure of personal information and abstention, but may also affect both the completeness and reliability of such information. Conceptually, omission of certain types of information can be regarded as a selective form of abstention. That is, consumers respond to perceived data protection threats in one of two ways; either by refusing to engage in direct marketing data capture requests altogether or by doing so selectively through the withholding of sensitive information. 
The primary reason for omission and falsification of personal information is concern that sensitive details might be disseminated to third parties leading to privacy intrusion in the form of unwanted communications such as mailings and telemarketing, frequently described as 'junk mail' and 'sales calls'. Consumers also omit and falsify information relating to what they perceive to be overly long or complicated questions in an effort to simplify the response process. In addition, misunderstanding and the desire to present socially desirable responses contribute towards falsification. Companies may thus be able to acquire more complete and reliable individual-level consumer information by emphasising data protection guarantees; by ensuring that data capture mechanics are concise and relevant; and by shortening and simplifying questions to reduce respondent fatigue and interpretation difficulties.

The findings of this study suggest a significant skew towards typically low levels of omission and falsification in volunteered personal information. Within this, consumers appear much more likely to omit than to falsify such information. Small changes in levels of omission and falsification can considerably reduce the efficiency of the direct marketing effort, however.

Finally, the incidence of personal information omission appears to be directly related to the incidence of falsification. Levels of omitted personal information can therefore serve as a useful indicator of levels of falsification. This is an important point because, whilst it is relatively easy to determine levels of omitted information, no obvious mechanism exists for establishing veracity. Where companies encounter higher levels of omission, it is more likely that information will also be falsified.

\section{FURTHER RESEARCH}

A number of testable predictions and areas for further research emerge from this study.

Generalisation of the results across the national population could be achieved by repeating the study using a sample size in excess of 1,000 personal interviewees.

This study postulates that data protection concerns affect the completeness and reliability of disclosed personal information, a finding that could be tested by comparing those consumers with high data protection concerns against those with low concerns. Those with high data protection concerns are expected to disclose a greater proportion of incomplete and falsified information than those with lower data protection concerns. Further empirical research in this area could be undertaken to verify the study's findings.

The findings of this study lead to the postulation that consumers omit personal information as a selective form of abstention. If correct, then abstention rates should co-vary with omission rates.

\section{References}

1 Robertshaw, G. S. (2000) 'The segmentation and targeting of consumers within the fragmenting UK mail order market', Journal of Segmentation in Marketing, Vol. 4, No. 1, pp. 27-51.

2 Wind, J. and Rangaswamy, A. (2001) 'Customerisation: The next revolution in mass customisation', Interactive Marketing: The International Journal of the Institute of Direct Marketing, Vol. 15, No. 1, pp. 13-32.

3 Courtheoux, R. J. (2000) 'Database marketing connects to the internet', Interactive Marketing: The International Journal of the Institute of Direct Marketing, Vol. 2, No. 2, pp. 129-137.

4 Zineldin, M. (2000) 'Beyond relationship marketing: Technologicalship marketing', Marketing Intelligence and Planning, Vol. 18, No. 1, pp. 9-23.

5 McCorkell, G. (1998) 'How marketing went direct', The Direct Marketing Guide, Volume 1, The Institute of Direct Marketing, Teddington, UK.

6 Lix, T. (1995) 'New customer acquisition: 
Prospecting models and the use of commercially available external data', Journal of Direct Marketing, Vol. 9, No. 4, pp. 9-20.

7 Reed, D. (1999) 'Consumer lifestyle data', Precision Marketing, 8th February, pp. 12-15.

8 Croft, M. (1997) 'Facts of life (Lifestyle databases)', Marketing Week, May 1st, pp. 43-45.

9 Gofton, K. (1999) 'Data firms react to survey fatigue', Marketing, 29th April, pp. 18-22.

10 Kleinman, M. (1999) 'News analysis', Precision Marketing, 16th November. pp. 10-11.

11 Robertshaw, G.S. (2005) 'What are the limitations in the gathering of individual-level consumer information for direct marketing purposes?' $\mathrm{PhD}$ thesis, Huddersfield University Business School, Huddersfield, UK, p. 62.

12 Peltier, J. and Schribrowsky, J. A. (1997) 'The use of need-based segmentation for developing segment-specific direct marketing strategies, Journal of Direct Marketing Customer Strategy Management, Vol. 11, No. 4, pp. 53-63.

13 Radford, M. (2004) 'Personal financial services in a digital age', Journal of Consumer Behaviour, Vol. 2, No. 3 pp. 287-296.

14 Lehman, D. R., Gupta, S. and Steckel, J. H. (1998) Marketing Research, Addison-Wesley, New York, NY.

15 Lehman et al. (1998) ibid. 